Review

\title{
Clinical Behavior of Short Dental Implants: Systematic Review and Meta-Analysis
}

\author{
Andrea Torres-Alemany, Lucía Fernández-Estevan*D, Rubén Agustín-Panadero $\mathbb{D}^{\text {, }}$ \\ José María Montiel-Company ${ }^{\mathbb{D}}$, Carlos Labaig-Rueda and José Félix Mañes-Ferrer \\ Department of Dental Medicine, Faculty of Medicine and Dentistry, University of Valencia, C/Gascó Oliag 1, \\ 46010 Valencia, Spain; anto.aleny@gmail.com (A.T.-A.); ruben.agustin@uv.es (R.A.-P.); \\ jose.maria.montiel@uv.es (J.M.M.-C.); Carlos.Labaig@uv.es (C.L.-R.); Jose.Manes@uv.es (J.F.M.-F.) \\ * Correspondence: lucia.fernandez-estevan@uv.es
}

Received: 7 September 2020; Accepted: 6 October 2020; Published: 12 October 2020

check for updates

\begin{abstract}
Short implants are an increasingly common alternative to other surgical techniques in areas where bone availability is reduced. Despite the advantages they offer, a variety of biological repercussions have been described in the literature that can even lead to the loss of these. The aim of this systematic review and meta-analysis was to analyze the impact of the use of short implants on their survival and on peri-implant bone loss, evaluating the influence that length, diameter, and crown-to-implant ratio (C/I) have on these parameters. This systematic review was based on guidelines proposed by the Preferred Reporting Items for Systematic Reviews and Meta-Analyses (PRISMA). An electronic search was conducted using terms related to the use of short implants in partially or totally edentulous patients. A total of five databases were consulted in the literature search: PubMed, Embase, Cochrane, Scopus, and Web of Science. After eliminating the duplicate articles and assessing which ones met the inclusion criteria, 15 articles were included for the qualitative analysis and 14 for the quantitative study. Through meta-analysis, the percentage of implant loss and peri-implant bone loss was estimated. Relating these parameters to length, diameter, and C/I ratio, no significant differences have been found for implant loss (values of $p=0.06,0.10$, and 0.9, respectively for length, diameter, and C/I ratio), nor for peri-implant bone loss (values of $p=0.71,0.72$, and 0.36 , respectively for length, diameter, and C/I ratio). In conclusion, the use of short implants does not seem to have a significant influence on marginal bone loss or the survival rate of implants.
\end{abstract}

Keywords: short implants; crown-to-implant ratio; survival rate; edentulous mouth; partially edentulous mouth

\section{Introduction}

The key to the success of dental implants is due to their osseointegration capacity [1], which can be defined as the direct contact of the implant surface with the bone, without the interposition of fibrous tissue. For good osseointegration, the implants must remain immobile when loading the prosthesis, and there may be vertical bone loss of up to $0.2 \mathrm{~mm}$ during the first year. When this bone loss is greater, there is a problem of osseointegration and periimplantitis may occur [2].

On the other hand, the teeth during their function perform a series of tension and compression forces that are transmitted to the surrounding alveolar bone. These forces cause the bone to be continuously stimulated, which is necessary to maintain its shape and density.

Therefore, when there is an absence of teeth, this lack of stimulation causes a decrease in bone density and volume, leading to a progressive reabsorption of the alveolar bone which in time leads to atrophy of the jaws [3]. This loss of bone volume at the level of the posterior maxilla and mandible can 
complicate rehabilitation with implants, since it leads to a reduction in the distance to the maxillary sinus and the lower dental nerve, respectively [4].

Various techniques have been used for many years to avoid damaging these structures, such as alveolar ridge augmentation procedures, bone grafting, tooth nerve transposition, or even zygomatic implants [1,4-6]. Bone grafting is one of the most widely used procedures, with implant success rates of up to $89 \%$ [7]. Although these procedures have high success rates, they can also have some drawbacks such as post-operative infections, collapse of mucosal tissue, pain, bleeding, and neurosensory deficits [8]. These are also complex procedures and advanced surgical techniques not applicable to all patients or by all professionals.

An alternative to these surgical treatments is the use of short implants in areas where bone availability is reduced. This treatment option has been included in numerous studies, using the survival of these implants as the main study variable [1,8-11].

The definition of a short implant has been a widely debated issue throughout the literature. Initially, short implants were considered to be those with a length of $<11 \mathrm{~mm}$. Later it has evolved and there are authors who consider them short when their length is $<7 \mathrm{~mm}$ and others when it is $<8 \mathrm{~mm}[6,12,13]$. In 2016, the European Consensus Conference established that short implants were those with an intraosseous length $\leq 8 \mathrm{~mm}$ and a diameter $\geq 3.75 \mathrm{~mm}$ [14].

Short implants have a number of advantages over standard implants; with short implants, less vertical bone grafting is performed, which means less time and cost of treatment and less morbidity for the patient. In addition, there is less surgical risk of perforating the maxillary sinus, of producing paresthesias due to dental nerve injury, of causing damage due to overheating during osteotomy, and of injuring the root of adjacent teeth.

Some studies suggest that the survival rate of short implants in the original bone is the same as that of standard implants placed through bone regeneration procedures [15,16]. But it should be noted that historically, short implants have been associated with a lower survival rate, with unpredictable results [6].

These implants also tend to have their crowns increased in length in order to establish occlusion with their antagonist, which causes an increase in the crown/implant ratio (C/I) [12,17].

Specifically, with short implants, increasing the height of the crown creates an unfavorable C/I ratio since the lever arm increases and when non-axial forces are received there is an increase in tension in the basal bone [12,17]. This is why the $\mathrm{C} / \mathrm{I}$ ratio was originally considered to be $1: 1$ as in natural teeth. However, some authors now suggest the possibility of using implants with a $\mathrm{C} / \mathrm{I}$ ratio greater than 1:1 without presenting long-term complications [18-21].

Based on the background described, the use of short implants, like all implants, can generate a series of complications in the patient among which we highlight, due to their relevance, the loss of the implant, and the loss of marginal bone. The use of short implants can be conditioned, among other things, by three aspects: the length of the implant itself, its diameter, and the C/I ratio generated with respect to the prosthesis it supports. Therefore, the main objective of this systematic review has been to analyze the available scientific evidence about the impact of the use of short implants in terms of implant survival and peri-implant bone loss. As secondary objectives, we set out to see if the scientific evidence provides us with information about the influence of length, diameter, and C/I ratio of short implants in terms of the biological complications mentioned above.

\section{Materials and Methods}

This bibliographic search was conducted following Preferred Reporting Items for Systematic Reviews and Meta-Analyses (PRISMA) guidelines for systematic reviews and meta-analyses. The review was also registered in the PRISMA database (PROSPERO: international prospective register of systematic reviews), registration number: CRD42020191093.

The population, intervention, comparison, outcome (PICO) question was: "Is the use of short implants with an increased crown-to-implant ratio an adequate treatment option compared to 
other treatment options in partially or totally edentulous patients?" with the following components: population: partially or totally edentulous patients; intervention: short implant placement with increased crown-to-implant ratio; comparison: other options that improve that crown-to-implant ratio, such as regeneration techniques or overdentures; and outcomes: implant failure/success, implant survival rate, prosthetic or biological complications.

An electronic search was conducted in the following databases: PubMed, Embase, Cochrane, Scopus and Web of Science. In order to focus the results on our PICO question, the search included several MeSH (Medical Subject Headings) terms: "mouth", "edentulous", "jaw", "bone regeneration", "bone transplantation", "denture", and "overlay." The Boolean operators applied were "OR" and "AND." The search terms were structured as follows: ((mouth, edentulous) OR (jaw, edentulous)) AND ((bone regeneration) OR (bone transplantation)) OR ((denture, overlay)).

Two researchers (A.T.A.; J.M.F.) conducted the database searches in duplicate independently. Titles and abstracts were selected by applying inclusion and exclusion criteria. One researcher (A.T.A) extracted data for relevant variables. The systematic review was carried out by (A.T.A) and the posterior meta-analysis was performed by a researcher not involved in the selection process (J.M.C).

Inclusion criteria: partially or totally edentulous patients treated with implants at the posterior level both maxillary and mandibular, studies with a minimum sample size of 10 patients, studies with a follow-up time of at least one year, studies using implants with a length of less than or equal to $8 \mathrm{~mm}$ as opposed to implants with a length greater than $8 \mathrm{~mm}$; in terms of studio design: randomized clinical trials (RCTs) and prospective case-control studies (PCC) and studies analyzing implant survival rate, implant failure, bone loss, presence of periimplantitis.

Exclusion criteria: animal or in vitro studies, pre-clinical studies and those describing clinical cases, case series, prospective cohort studies and retrospective studies, studies with insufficient information, those that use the same population group (since in this case we will only use the study with the longest follow-up period), and the studies in which the prosthesis is supported at the same time by short and standard implants.

The variables registered in each of the studies were: author and year of publication; type of study; years of follow-up; number of patients and initial implants; location, length, and diameter of the implants; type of restoration (cemented or screwed); splinted or non-splinted restorations; prosthetic complications; mean marginal bone loss and standard deviation (SD); number of lost implants; percentage of implant survival; and crown-to-implant ratio (C/I ratio).

The quality of the studies was independently analyzed by the same researchers. To evaluate the quality of the cohort studies the Newcastle-Ottawa Quality Evaluation Scale (NOS) was used [22].

The biological repercussions studied for the meta-analysis were the percentage of implant loss and the mean marginal bone loss around the implant. The studies were combined using a random effects model with the inverse of the variance method. For all the estimated variables we calculated their $95 \%$ confidence interval and their prediction interval. Heterogeneity among the combined studies was assessed by $\mathrm{Q}$ test $(p<0.05)$ and was quantified with I2 considering a slight heterogeneity if it was between $25-50 \%$, moderate between $50-75 \%$, and high if $>75 \%$. A subgroup analysis was performed to assess the existence of differences due to diameter, length, $\mathrm{C} / \mathrm{I}$ ratio, and follow-up time using the $\mathrm{Q}$ test; and a meta-regression was performed using the mixed effects model. The existence of significant variables was also assessed by means of the $Q M$ value ( $Q$ test of moderators value). The existence of statistical significance was established for a $p<0.05$. The meta-analyses have been represented with forest plot; and the publication bias has been assessed by means of the Trim and Fill adjustment method, and are represented with Funnel plots.

\section{Results}

The initial electronic search identified 300 articles in PubMed, 126 in Embase, 110 in Cochrane, 120 in Scopus, and 65 in Web of Science; which together with the 20 articles derived from the manual search make a total of 741 articles. Of all the articles derived from the initial search, we proceeded to 
manually eliminate the articles that were duplicated in the different databases. In this way, a total of 89 articles were eliminated. Once we eliminated the duplicates, we proceeded to read the title and abstract of the remaining 652 articles, of which 513 were excluded. After this exclusion, we were left with 139 potential articles to include in this review for full text reading. After reading these 139 articles, we proceeded to discard 124 articles for not presenting relevant data for the review and for not meeting the inclusion criteria described above; that is why the review finally included a total of 15 articles, which meet the inclusion criteria, and from which the qualitative analysis has been carried out. In order to carry out the quantitative analysis, we discarded one of the articles because of insufficient information, leaving 14 articles. In Figure 1 is the PRISMA flow chart, where the selection process of the articles is represented.

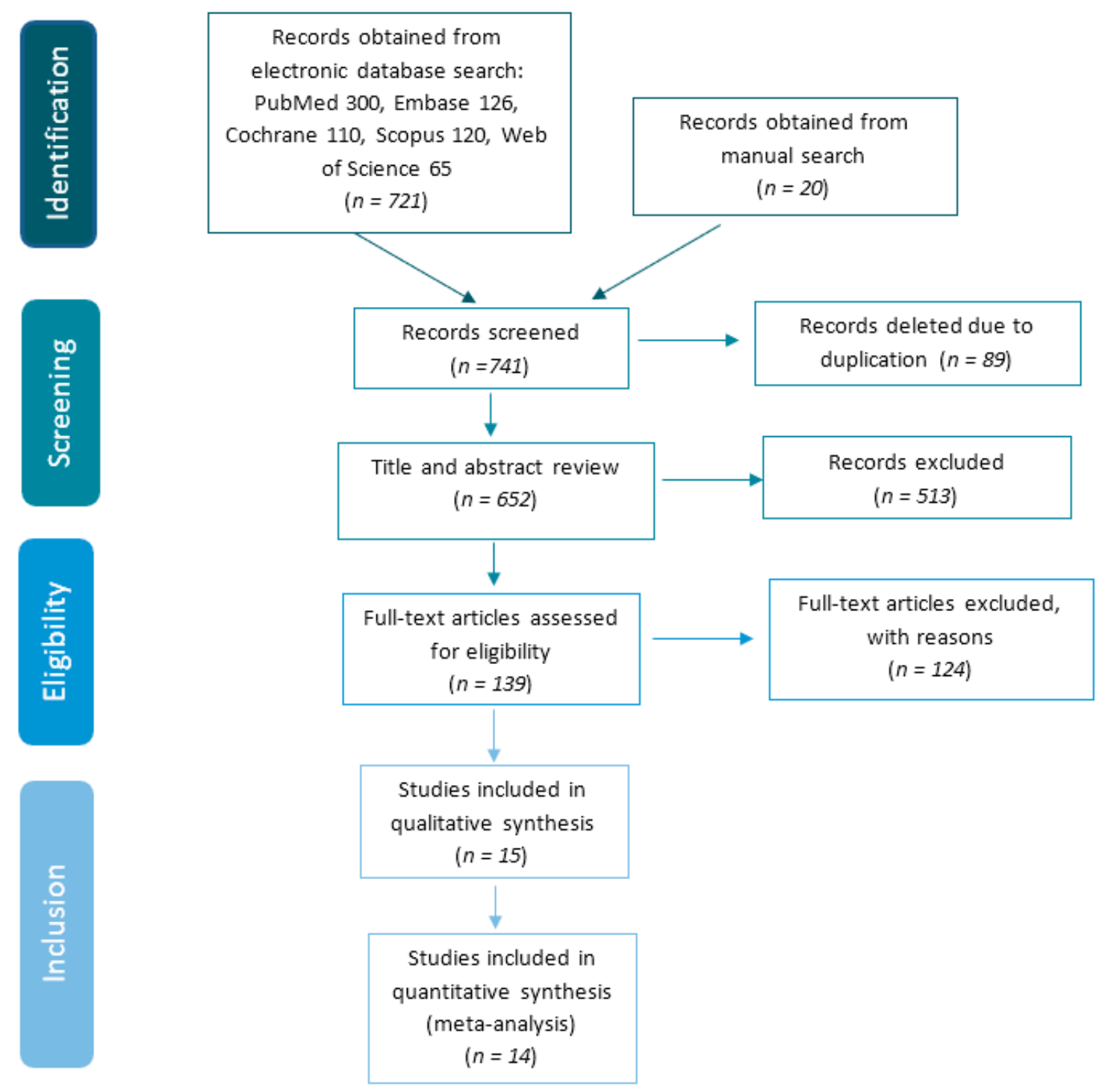

Figure 1. Flow chart of study selection procedure.

The results of methodological quality assessment using the Newcastle-Ottawa (NOS) Scale are shown in Table 1. We can see that the quality of the selected studies is high, being all of them above the value 7 . 
Table 1. Quality of the studies in the Newcastle-Ottawa Scale for cohort studies.

\begin{tabular}{|c|c|c|c|c|c|c|c|c|c|c|}
\hline \multirow{2}{*}{$\begin{array}{l}\text { AUTHOR } \\
\text { (Year) }\end{array}$} & \multicolumn{4}{|c|}{$\underset{(* * * *)}{\text { SELECTION }}$} & \multicolumn{2}{|c|}{$\begin{array}{l}\text { COMPARABILITY } \\
(* *)\end{array}$} & \multicolumn{3}{|c|}{$\begin{array}{l}\text { OUTCOMES } \\
\left(_{(* * *)}\right.\end{array}$} & \multirow[t]{2}{*}{ TOTAL } \\
\hline & 1 & 2 & 3 & 4 & $5 a$ & $5 b$ & 6 & $\begin{array}{c}7 \\
\text { (1 year) }\end{array}$ & 8 & \\
\hline Adánez et al. (2018) & & $*$ & $*$ & * & $*$ & $*$ & * & * & * & 8 \\
\hline Blanes et al. (2007) & $*$ & $*$ & $*$ & * & $*$ & * & * & * & & 8 \\
\hline Ghariani et al. (2016) & & $*$ & * & * & $*$ & & * & * & * & 7 \\
\hline Guarnieri et al. (2019) & $*$ & * & $*$ & * & * & $*$ & * & * & * & 9 \\
\hline Hadzik et al. (2018) & * & $*$ & $*$ & * & $*$ & & * & * & & 7 \\
\hline Malchiodi et al. (2014) & * & * & * & * & $*$ & * & * & * & * & 9 \\
\hline Malchiodi et al. (2017) & * & * & * & * & * & & * & * & * & 8 \\
\hline Mangano et al. (2016) & $*$ & * & * & * & * & & * & * & * & 8 \\
\hline Naenni et al. (2018) & $*$ & $*$ & $*$ & * & $*$ & $*$ & $*$ & * & $*$ & 9 \\
\hline Pohl et al. (2017) & $*$ & * & $*$ & * & * & $*$ & * & * & & 8 \\
\hline Rossi et al. (2016) & * & * & * & * & $*$ & $*$ & * & * & * & 9 \\
\hline Sahrmann et al. (2016) & $*$ & $*$ & $*$ & * & $*$ & $*$ & $*$ & * & $*$ & 9 \\
\hline Schincaglia et al. (2015) & * & $*$ & * & * & $*$ & $*$ & * & * & * & 9 \\
\hline Zadeh et al. (2017) & * & * & * & * & * & $*$ & * & * & * & 9 \\
\hline
\end{tabular}

Criteria: (1) Representativeness of the exposed cohort. (2) Selection of the non-exposed cohort. (3) Ascertainment of exposure. (4) Demonstration that outcome of interest was not present at start of study. (5) Comparability of cohorts on the basis of the design or analysis controlled for confounders: for the most important factor (5a), for other factors (5b). (6) Assessment of outcome. (7) Adequate follow-up time. (8) Adequacy of follow-up of cohorts.

The quantitative synthesis included 14 articles (Table 2). The variables presented in the table are: author and year of publication, type of study, years of follow-up, number of initial implants, length and diameter of the implants, mean marginal bone loss and standard deviation (SD), number of lost implants, crown-to-implant ratio (C/I ratio) and the assessment of the articles according to the Newcastle-Ottawa Scale.

In the table we indicate the type of article that has been included, whether they are prospective control case studies (PCC) or randomized clinical trials (RCT). Through quantitative analysis we wanted to estimate on the one hand the percentage of implant loss, and on the other hand, the average marginal bone loss around the implant.

Both parameters were related to the length and diameter of the implant, as well as the C/I ratio, which are the fundamental objectives of our work.

To carry out this analysis we eliminated an article, Kim et al. 2015 [23], because it presented insufficient information to obtain these data.

These two variables were studied separately, using 14 studies to determine the percentage of implant failure or loss, and 10 studies to estimate the mean marginal bone loss. 
Table 2. Quantitative analysis of articles included in the systematic review.

\begin{tabular}{|c|c|c|c|c|c|c|c|c|c|c|c|}
\hline $\begin{array}{l}\text { AUTHOR } \\
\text { (YEAR) }\end{array}$ & $\begin{array}{l}\text { TYPE OF } \\
\text { STUDY }\end{array}$ & $\begin{array}{l}\text { YEARS OF } \\
\text { FOLLOW-UP }\end{array}$ & $\begin{array}{l}\text { LENGTH * } \\
\quad(\mathrm{mm})\end{array}$ & $\begin{array}{l}\text { DIAMETER } \\
* *(\mathrm{~mm})\end{array}$ & $\begin{array}{l}\text { No. INITIAL } \\
\text { IMPLANTS }\end{array}$ & $\begin{array}{c}\text { MEAN } \\
\text { MARGINAL } \\
\text { BONE LOSS } \\
(\mathrm{mm})\end{array}$ & SD & $\begin{array}{c}\text { S/NS } \\
\text { RESTORATIONS }\end{array}$ & $\begin{array}{l}\text { No. LOST } \\
\text { IMPLANTS }\end{array}$ & C/I RATIO & NOS \\
\hline \multirow{2}{*}{$\begin{array}{l}\text { Adánez } \\
\text { (2018) }\end{array}$} & \multirow{2}{*}{ PCC } & \multirow{2}{*}{1} & Short & Standard & 20 & $0^{\prime} 56$ & $0^{\prime} 51$ & $\mathrm{~S}$ & 0 & 2 & \multirow{2}{*}{8} \\
\hline & & & Standard & Standard & 20 & $0^{\prime} 67$ & $0^{\prime} 23$ & $S$ & 0 & 1 & \\
\hline \multirow{2}{*}{$\begin{array}{l}\text { Blanes } \\
(2007)\end{array}$} & \multirow{2}{*}{ PCC } & \multirow{2}{*}{10} & Short & Standard & 108 & $0^{\prime} 5$ & $0^{\prime} 63$ & $\mathrm{~S}$ and NS & 3 & 1 & \multirow{2}{*}{8} \\
\hline & & & Standard & Standard & 84 & $0^{\prime} 3$ & $0^{\prime} 48$ & $\mathrm{~S}$ and NS & 1 & 2 & \\
\hline \multirow{2}{*}{$\begin{array}{l}\text { Ghariani } \\
\text { (2016) }\end{array}$} & \multirow{2}{*}{ PCC } & \multirow{2}{*}{1} & Short & Standard & 5 & & & NS & 0 & 3 & \multirow{2}{*}{7} \\
\hline & & & Standard & Standard & 7 & & & NS & 0 & 2 & \\
\hline \multirow{2}{*}{$\begin{array}{c}\text { Guarnieri } \\
\text { (2019) }\end{array}$} & \multirow{2}{*}{ PCC } & \multirow{2}{*}{3} & Short & Standard & 28 & $0^{\prime} 23$ & $0^{\prime} 6$ & $\mathrm{~S}$ and NS & 1 & & \multirow{2}{*}{9} \\
\hline & & & Standard & Standard & 36 & $0^{\prime} 27$ & $0^{\prime} 3$ & $\mathrm{~S}$ and NS & 0 & & \\
\hline \multirow{2}{*}{$\begin{array}{c}\text { Hadzik } \\
(2018)\end{array}$} & \multirow{2}{*}{ PCC } & \multirow{2}{*}{3} & Short & Standard & 15 & $0^{\prime} 34$ & $0^{\prime} 24$ & NS & 1 & 2 & \multirow{2}{*}{7} \\
\hline & & & Standard & Standard & 15 & $0^{\prime} 22$ & $0^{\prime} 46$ & NS & 0 & 2 & \\
\hline \multirow{2}{*}{$\begin{array}{l}\text { Malchiodi } \\
\text { (2014) }\end{array}$} & \multirow{2}{*}{ PCC } & \multirow{2}{*}{3} & Short & Standard & 151 & & & $\mathrm{~S}$ and NS & 3 & & \multirow{2}{*}{9} \\
\hline & & & Standard & Standard & 108 & & & S and NS & 2 & & \\
\hline \multirow{8}{*}{$\begin{array}{l}\text { Malchiodi } \\
\quad \text { (2017) }\end{array}$} & \multirow{8}{*}{ PCC } & \multirow{8}{*}{3} & Short & Standard & 11 & $0^{\prime} 44$ & $0^{\prime} 72$ & $\mathrm{~S}$ and NS & 1 & 3 & \multirow{8}{*}{8} \\
\hline & & & Standard & Narrow & 10 & $0^{\prime} 46$ & $0^{\prime} 37$ & $\mathrm{~S}$ and NS & 1 & 2 & \\
\hline & & & Standard & Standard & 18 & $0^{\prime} 46$ & $0^{\prime} 37$ & $\mathrm{~S}$ and NS & 0 & 2 & \\
\hline & & & Standard & Standard & 9 & $0^{\prime} 46$ & $0^{\prime} 37$ & S and NS & 0 & 2 & \\
\hline & & & Standard & Standard & 2 & $0^{\prime} 46$ & $0^{\prime} 37$ & S and NS & 0 & 2 & \\
\hline & & & Standard & Narrow & 12 & $0^{\prime} 75$ & $0^{\prime} 86$ & $\mathrm{~S}$ and NS & 2 & 2 & \\
\hline & & & Standard & Standard & 18 & $0^{\prime} 75$ & $0^{\prime} 86$ & $\mathrm{~S}$ and NS & 0 & 2 & \\
\hline & & & Standard & Standard & 10 & $0^{\prime} 75$ & $0^{\prime} 86$ & $\mathrm{~S}$ and NS & 0 & 2 & \\
\hline $\begin{array}{c}\text { Mangano } \\
(2016)\end{array}$ & PCC & 5 & Short & Standard & 68 & & & $\mathrm{~S}$ and NS & 2 & 2 & 8 \\
\hline \multirow{2}{*}{$\begin{array}{c}\text { Naenni } \\
\text { (2018) }\end{array}$} & \multirow{2}{*}{$\mathrm{RCT}$} & \multirow{2}{*}{5} & Short & Standard & 40 & & & NS & 4 & 2 & 0 \\
\hline & & & Standard & Standard & 46 & & & NS & 0 & 2 & $y$ \\
\hline
\end{tabular}


Table 2. Cont

\begin{tabular}{|c|c|c|c|c|c|c|c|c|c|c|c|}
\hline $\begin{array}{l}\text { AUTHOR } \\
\text { (YEAR) }\end{array}$ & $\begin{array}{l}\text { TYPE OF } \\
\text { STUDY }\end{array}$ & $\begin{array}{l}\text { YEARS OF } \\
\text { FOLLOW-UP }\end{array}$ & $\begin{array}{l}\text { LENGTH * } \\
\quad(\mathrm{mm})\end{array}$ & $\begin{array}{l}\text { DIAMETER } \\
* *(\mathrm{~mm})\end{array}$ & $\begin{array}{l}\text { No. INITIAL } \\
\text { IMPLANTS }\end{array}$ & $\begin{array}{c}\text { MEAN } \\
\text { MARGINAL } \\
\text { BONE LOSS } \\
(\mathrm{mm})\end{array}$ & SD & $\begin{array}{c}\text { S/NS } \\
\text { RESTORATIONS }\end{array}$ & $\begin{array}{l}\text { No. LOST } \\
\text { IMPLANTS }\end{array}$ & C/I RATIO & NOS \\
\hline \multirow{2}{*}{ Pohl (2017) } & \multirow{2}{*}{$\mathrm{RCT}$} & \multirow{2}{*}{3} & Short & Standard & 61 & $0^{\prime} 44$ & $0^{\prime} 44$ & NS & 0 & 2 & \multirow{2}{*}{8} \\
\hline & & & Standard & Standard & 68 & $0^{\prime} 45$ & $0^{\prime} 55$ & NS & 0 & 1 & \\
\hline \multirow{2}{*}{$\begin{array}{l}\text { Rossi } \\
\text { (2016) }\end{array}$} & \multirow{2}{*}{ PCC } & \multirow{2}{*}{5} & Short & Standard & 30 & $2^{\prime} 3$ & $0^{\prime} 52$ & NS & & 2 & \multirow{2}{*}{9} \\
\hline & & & Standard & Standard & 30 & $2^{\prime} 64$ & $0^{\prime} 56$ & NS & & 1 & \\
\hline \multirow{2}{*}{$\begin{array}{l}\text { Sahrmann } \\
\quad(2016)\end{array}$} & \multirow{2}{*}{$\mathrm{RCT}$} & \multirow{2}{*}{3} & Short & & 40 & $0^{\prime} 19$ & $0^{\prime} 62$ & NS & 1 & 2 & \multirow{2}{*}{9} \\
\hline & & & Standard & & 38 & $0^{\prime} 33$ & $0^{\prime} 71$ & NS & 0 & 2 & \\
\hline \multirow{2}{*}{$\begin{array}{l}\text { Schincaglia } \\
\text { (2015) }\end{array}$} & \multirow{2}{*}{$\mathrm{RCT}$} & \multirow{2}{*}{1} & Short & Standard & 67 & $0^{\prime} 22$ & $0^{\prime} 3$ & NS & 2 & 2 & \multirow{2}{*}{9} \\
\hline & & & Standard & Standard & 70 & $0^{\prime} 37$ & $0^{\prime} 59$ & NS & 1 & 1 & \\
\hline \multirow{2}{*}{$\begin{array}{l}\text { Zadeh } \\
(2018)\end{array}$} & \multirow{2}{*}{$\mathrm{RCT}$} & \multirow{2}{*}{3} & Short & Standard & 108 & $0^{\prime} 27$ & $0^{\prime} 4$ & $S$ & 4 & 2 & \multirow{2}{*}{9} \\
\hline & & & Standard & Standard & 101 & $0^{\prime} 44$ & $0^{\prime} 74$ & $S$ & 1 & 1 & \\
\hline
\end{tabular}

SD: standard deviation; C/I ratio: crown-to-implant ratio; S: splinted; NS: non-splinted; NOS: Newcastle-Ottawa Scale; PCC: prospective control case studies; RCT: randomized clinical trial. ${ }^{*}$ Length: short $\leq 8 \mathrm{~mm}$ and standard $>8 \mathrm{~mm}$. ${ }^{* *}$ Diameter: standard $(\geq 3.75 \mathrm{~mm})$ and narrow $<3.75 \mathrm{~mm}$. 


\subsection{Percentage of Failure or Implant Loss}

Data from 14 studies have been combined using a random effects model with the inverse of variance method (Figure 2), estimating an implant failure rate of 1.3\% (Confidence Interval-95\% between $0.63 \%$ and $1.97 \%$ ) and a prediction interval between $0.61 \%$ and $2 \%$. No heterogeneity was detected among the combined studies (test $Q=22.7 ; p$-value $=0.909 ; \mathrm{I}^{2}=0 \%$ ).
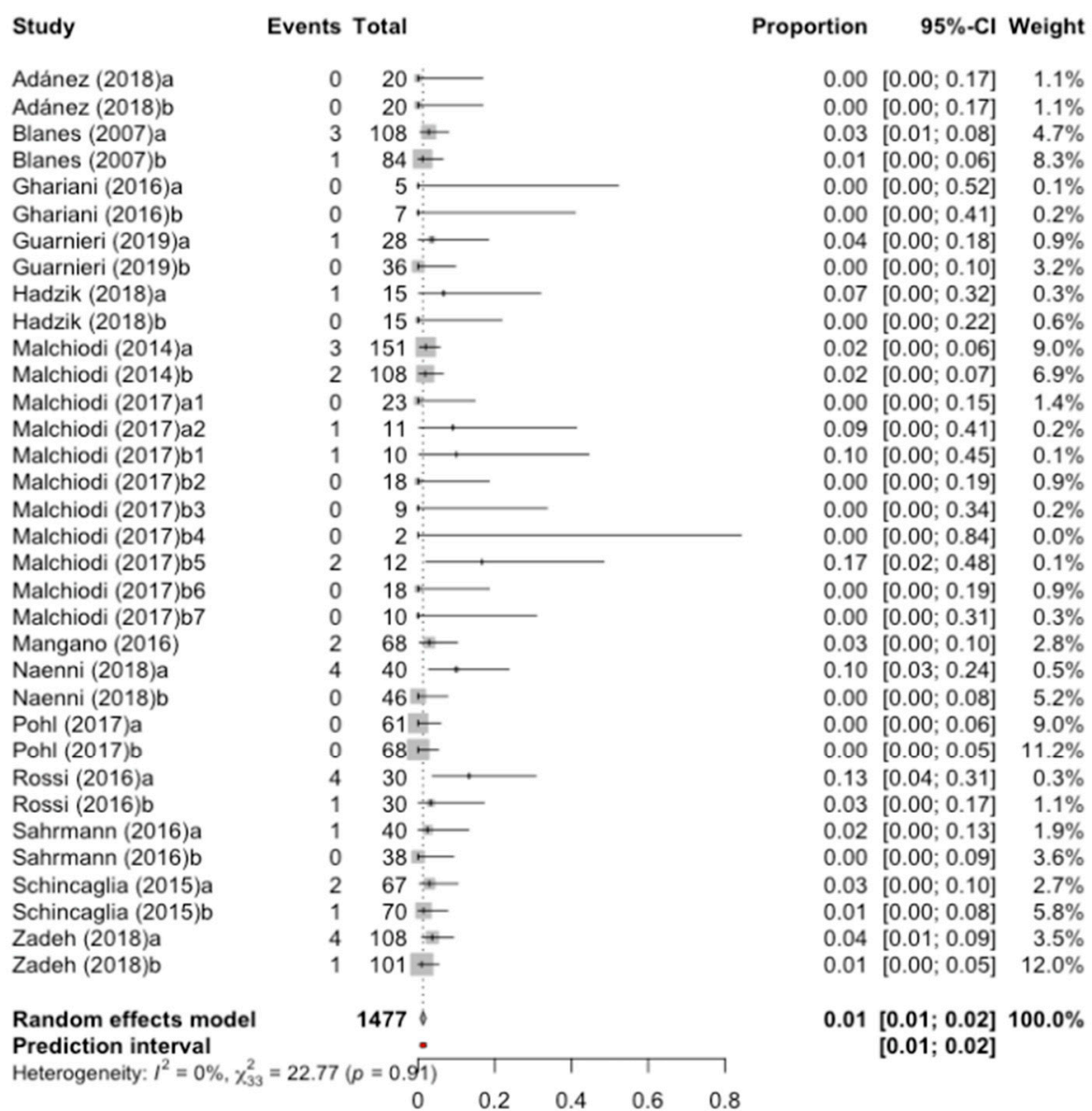

Figure 2. Forest plot of the meta-analysis of the implant failure rate. CI is the $95 \%$ confidence interval of the percentage of failure or implant loss.

\subsection{Analysis by Subgroups According to C/I Ratio}

The percentage of failure in implants with a $\mathrm{C} / \mathrm{I}$ ratio $=1$ was $1.03 \%$, with $\mathrm{C} / \mathrm{I}$ ratio $=2$ it was $1.36 \%$, and finally for a $\mathrm{C} / \mathrm{I}$ ratio $=3$ it was $0.87 \%$ (Figure 3 ).

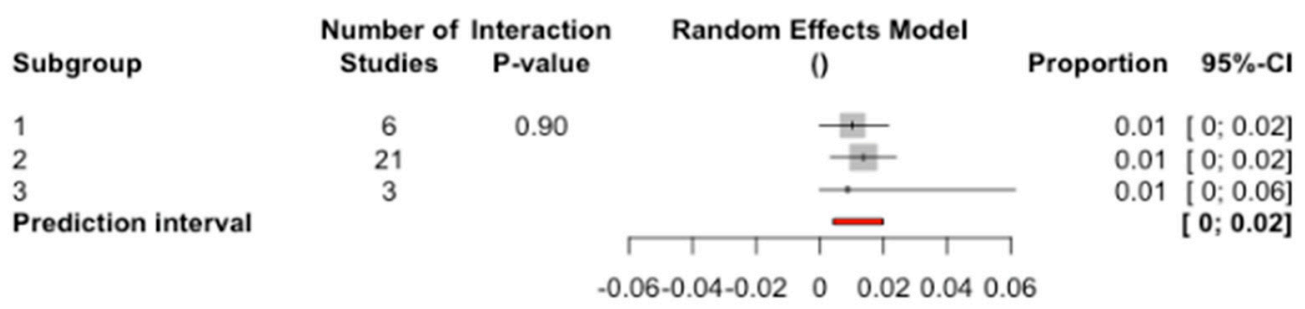

Figure 3. Forest plot of the meta-analysis of the percentage of implant failure according to crown-to-implant (C/I) ratio.

There were no significant differences between the subgroups ( $Q$ test $=21.3 ; p$-value $=0.902$ ). 


\subsection{Analysis by Subgroups According to Diameter}

The percentage of failure in implants with standard diameter was $1.28 \%$, while with narrow diameter it was $12.9 \%$ (Figure 4), although no significant differences between subgroups were detected $(\mathrm{Q}$ test $=2.67 ; p$-value $=0.102)$.

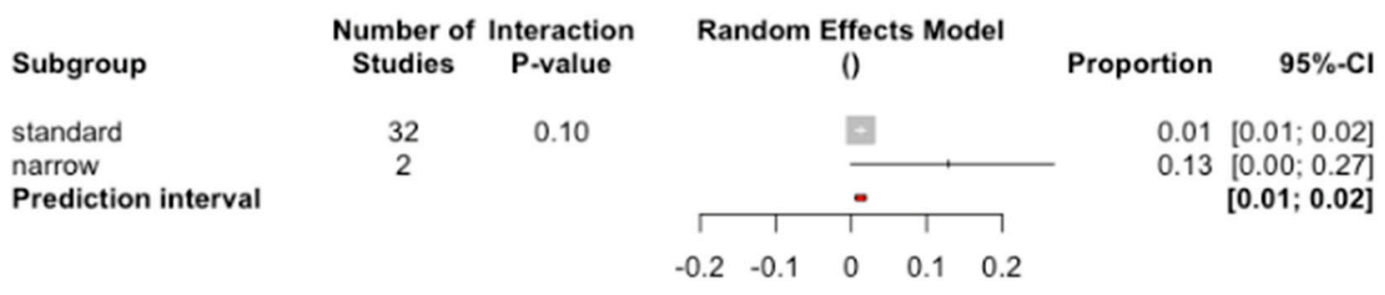

Figure 4. Forest plot of the meta-analysis of the percentage of implant failure according to diameter.

\subsection{Analysis by Subgroups According to Length}

The failure rate for short implants was $2.11 \%$, while with long implants it was $0.8 \%$ (Figure 5). There were no significant differences between the subgroups ( $Q$ test $=3.46 ; p$-value $=0.063$ ) although its value was very close to significance.

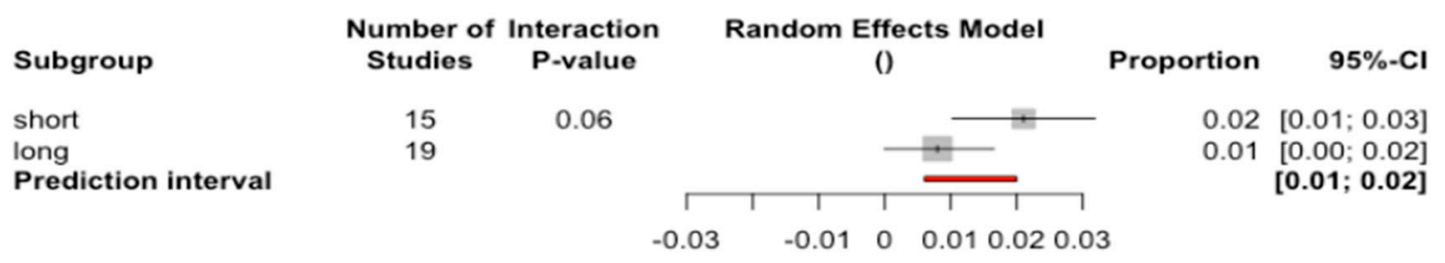

Figure 5. Forest plot of the meta-analysis of the percentage of implant failure according to the length.

\subsection{Meta-Regression}

Using a combination model of mixed effect studies, the C/I ratio, diameter, implant length, and years of follow-up have been analyzed in the proportion of implant loss (Table 3). The moderator's test showed $\mathrm{QM}$ value $=14.38$ and $p$-value $=0.230$, indicating that none of the variables were significant in the model.

Table 3. Estimation of the moderators of the meta-regression.

\begin{tabular}{cccc}
\hline & Estimator & IC-95\% & $p$-Value \\
\hline Intercept & 0.131 & $-0.009 ; 0.272$ & 0.067 \\
\hline Standard diameter & -0.126 & $-0.267 ; 0.014$ & 0.077 \\
\hline C/I ratio $=2$ & -0.005 & $-0.022 ; 0.012$ & 0.558 \\
\hline C/I ratio $=3$ & -0.016 & $-0.072 ; 0.040$ & 0.577 \\
\hline Years of follow-up & 0.001 & $-0.002 ; 0.004$ & 0.485 \\
\hline Short length & 0.017 & $-0.001 ; 0.035$ & 0.055 \\
\hline
\end{tabular}

$\mathrm{CI}$ is the $95 \%$ confidence interval of the percentage of implant loss according to diameter, C/I ratio and length of the implants.

\subsection{Publication Bias}

The Trim and Fill method was used to assess the publication bias (Figure 6). Using a random effects model (inverse variance method), five studies were added to adjust the asymmetry of the Funnel plot, obtaining an estimate of the failure rate of $1.18 \%$ (CI-95\% between $0.52 \%$ and $1.87 \%$ ) which does 
not differ from the initial estimate of $1.3 \%$ (CI-95\% between $0.63 \%$ and $1.97 \%$ ), making it possible to rule out the existence of publication bias.
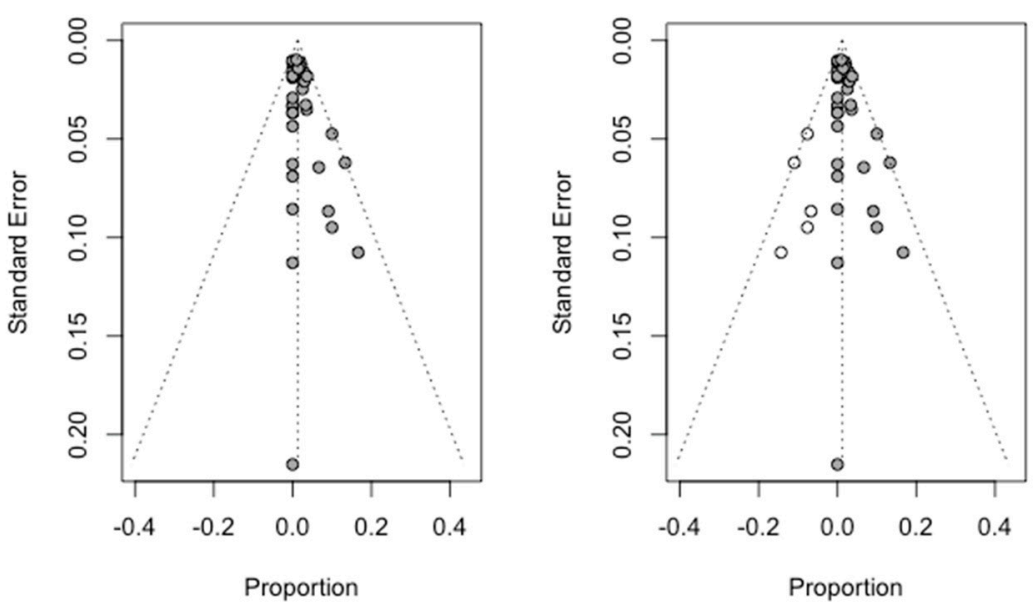

Figure 6. Initial funnel plot and after Trim and Fill adjustment of the implant failure percentage.

\subsection{Mean Marginal Bone Loss from the Implant}

Data from 10 studies were combined using a random effects model with the inverse method of variance, estimating a mean marginal bone loss to the implant of $0.58 \mathrm{~mm}(95 \%$ CI between $0.40 \mathrm{~mm}$ and $0.75 \mathrm{~mm}$ ) and a predictive range of $-0.36 \mathrm{~mm}$ to $1.52 \mathrm{~mm}$ (Figure 7). There is high heterogeneity among the combined studies (test $\mathrm{Q}=965.9 ; p$-value $<0.01 ; \mathrm{I}^{2}=97 \%$ ).

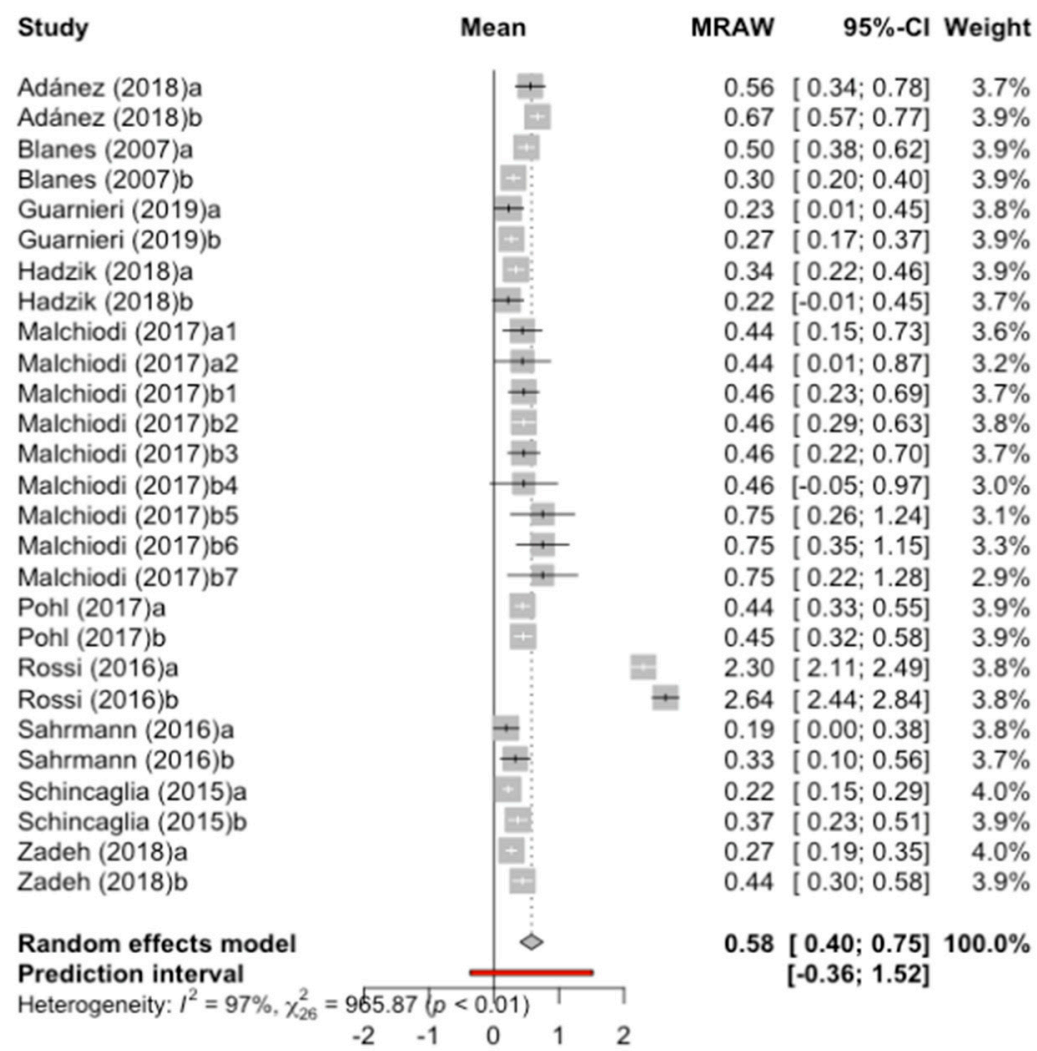

Figure 7. Forest plot of the meta-analysis of marginal bone loss at the implant. MRAW is the crude mean. 


\subsection{Analysis by Subgroups According to C/I ratio}

The mean marginal bone loss to the implant when $\mathrm{C} / \mathrm{I}$ ratio $=1$ was $0.84 \mathrm{~mm}$, with $\mathrm{C} / \mathrm{I}$ ratio $=2$ was $0.54 \mathrm{~mm}$, and finally for a $\mathrm{C} / \mathrm{I}$ ratio $=3$ of 0.44 (Figure 8). No significant differences were detected between the three subgroups $(\mathrm{Q}$ test $=2.05 ; p$-value $=0.359$ ).

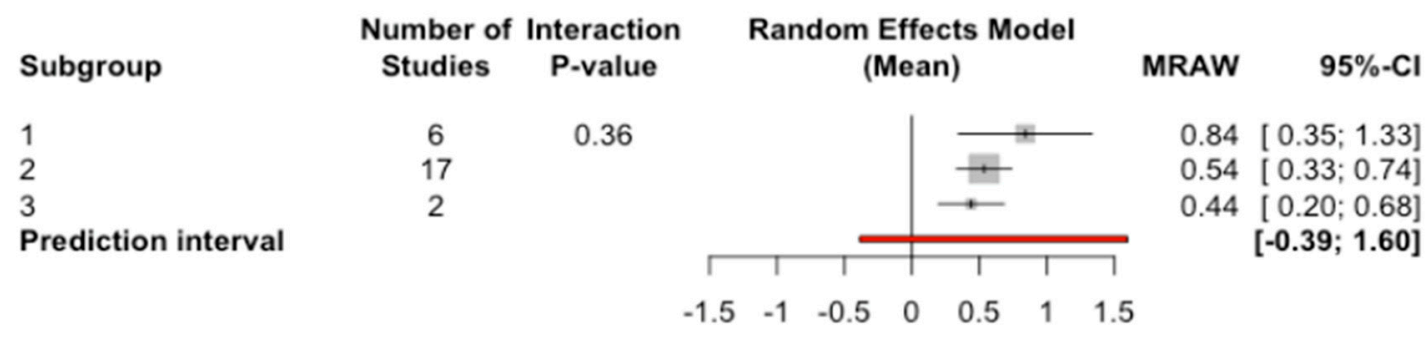

Figure 8. Forest plot of the meta-analysis of marginal bone loss at the implant according to C/I ratio.

\subsection{Analysis by Subgroups According to Diameter}

The average marginal bone loss to the implant with standard diameter was $0.52 \mathrm{~mm}$, while with narrow diameter it was $0.58 \mathrm{~mm}$ (Figure 9). Although no significant differences between the subgroups were detected $(\mathrm{Q}$ test $=0.13 ; p$-value $=0.715)$.

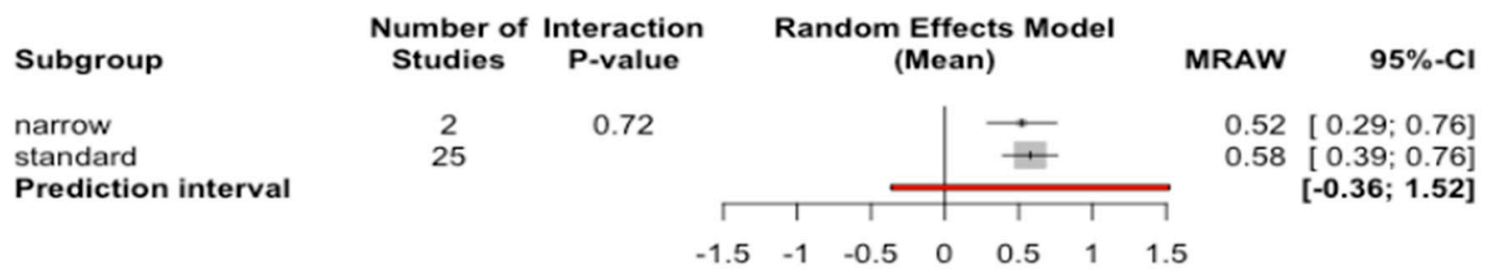

Figure 9. Forest plot of the meta-analysis of marginal bone loss to the implant according to diameter.

\subsection{Analysis by Subgroups According to Length}

The average marginal bone loss to the implant of short length was $0.54 \mathrm{~mm}$, while with long length it was $0.61 \mathrm{~mm}$ (Figure 10). No significant differences between the long and short implant subgroups were determined $(\mathrm{Q}$ test $=0.14 ; p$-value $=0.713)$.

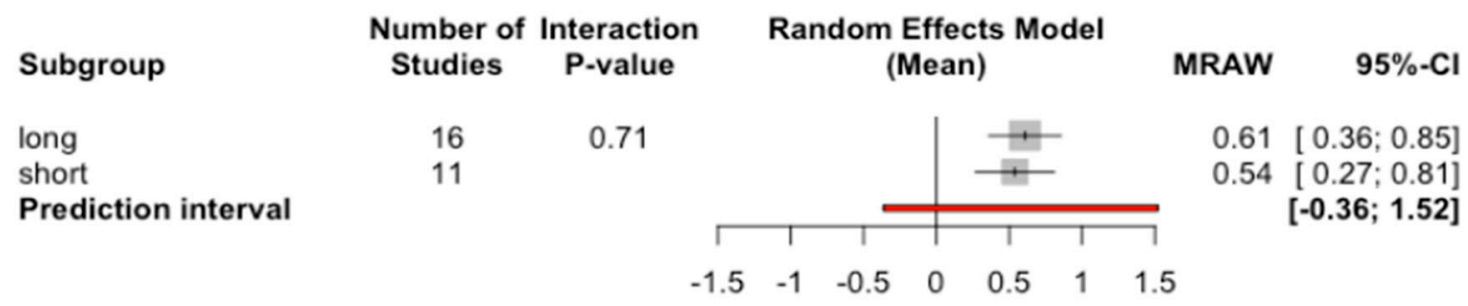

Figure 10. Forest plot of the meta-analysis of marginal bone loss to the implant according to length.

\subsection{Meta-Regression}

Using a combination model of mixed effect studies, the $\mathrm{C} / \mathrm{I}$ ratio, diameter, implant length, and years of follow-up on mean marginal bone loss to the implant were analyzed (Table 4). The moderator test showed a QM value of 1.82 and $p=0.872$, indicating that none of the variables showed significance in the model. 
Table 4. Estimation of the moderators of the meta-regression.

\begin{tabular}{cccc}
\hline & Estimator & IC-95\% & $p$-Value \\
\hline intercept & 0.975 & $-0.002 ; 1.952$ & 0.050 \\
\hline Standard diameter & -0.084 & $-0.937 ; 0.768$ & 0.845 \\
\hline C/I ratio $=2$ & -0.322 & $-0.849 ; 0.204$ & 0.230 \\
\hline C/I ratio $=3$ & -0.453 & $-1.424 ; 0.517$ & 0.360 \\
\hline Years of follow-up & -0.019 & $-0.114 ; 0.075$ & 0.685 \\
\hline Short length & 0.061 & $-0.433 ; 0.556$ & 0.807 \\
\hline
\end{tabular}

\subsection{Publication Bias}

The Trim and Fill method to adjust the asymmetry of the Funnel plot was used adding 11 new studies to those initially combined to obtain a symmetrical image. The new estimate of the mean marginal bone loss to the implant was $0.32 \mathrm{~mm}$ (IC-95\% between 0.12 and $0.51 \mathrm{~mm}$ ) which differs slightly from the mean initially obtained and estimated at $0.58 \mathrm{~mm}$ (IC-95\% between $0.40 \mathrm{~mm}$ and $0.75 \mathrm{~mm}$ ). The Figure 11 shows the two Funnel plots (initial and adjusted) indicating a slight but not significant difference between their confidence intervals and indicating a small probability of publication bias.
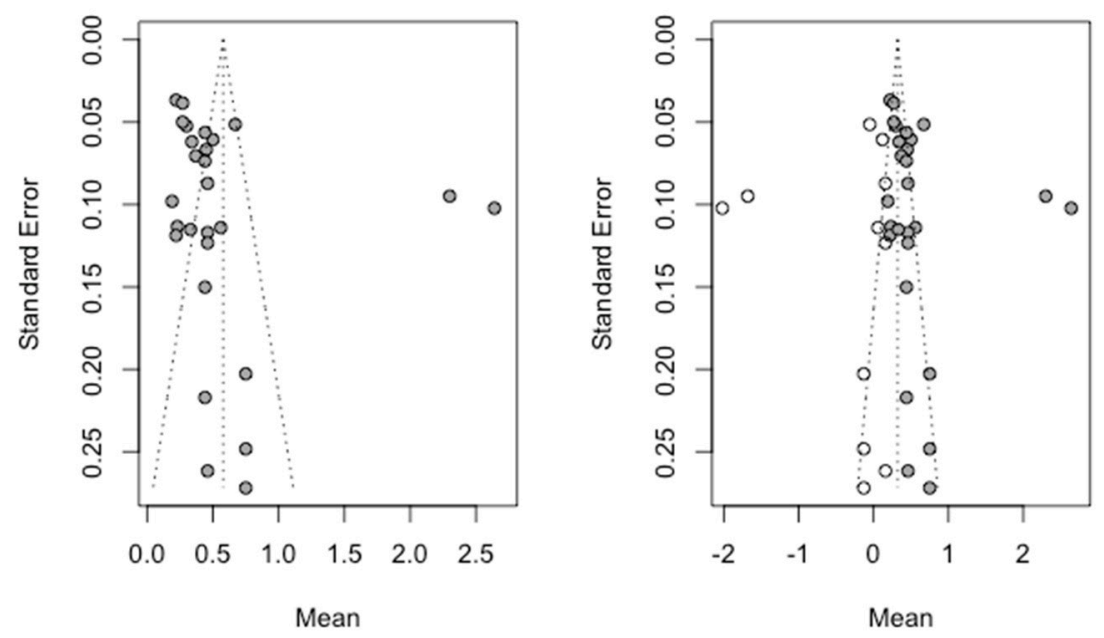

Figure 11. Funnel plot initial and after Trim and Fill adjustment.

\section{Discussion}

Nowadays, it is very common to use short implants in order to avoid surgical techniques that may represent a risk for important anatomical structures. As we have pointed out, in the literature there have been many diverse opinions about the complications that may result from the use of short implants when there is an increased crown-to-implant (C/I) ratio, such as the marginal bone loss that may occur, or even the loss of the implants.

According to the results obtained in the quantitative analysis, it has been estimated that the percentage of implant loss is $1.3 \%$ and the average annual marginal bone loss is $0.58 \mathrm{~mm}$. It has been established that none of the variables to which both parameters were related, such as length, diameter, C/I ratio, and follow-up time, affect the results significantly.

Adánez [24] and Guarnieri [25] in their studies intended to compare the marginal bone loss between short and standard implants. They also evaluated the survival of short implants in relation to the C/I ratio. Finally, both found that there was no significant difference between implant survival rate and marginal bone loss when the $\mathrm{C} / \mathrm{I}$ ratio was increased. The same conclusion was reached 
by Sarhmann [26] and Hadzik [27], whose studies determined that the C/I ratio had no significant influence on the implant survival rate and marginal bone loss.

Ghariani et al. [28] also wanted to evaluate the survival rate and marginal bone loss on implants with different $\mathrm{C} / \mathrm{I}$ ratios. In this case, although there was a trend towards greater marginal bone loss with an increased C/I ratio, the results were not statistically significant. Nor did they see any influence on implant survival.

In 2017, Malchiodi et al. [29] conducted a study in which they analyzed the survival rate and marginal bone loss between short and standard implants. They found that the C/I ratio was not significantly related to bone loss or implant loss. Neither the diameter nor the length of the implants had any influence.

Mangano et al. [30] aimed to evaluate the influence that C/I ratio had on marginal bone loss, on prosthetic complications, and on the survival of short implants. Although complications were more frequent in restorations with a C/I ratio greater than 2, no significant differences were seen. Nor was there any difference in marginal bone loss or survival rate.

Pohl et al. [31] studied the survival of short implants compared to standard implants over a 3-year follow-up period. They observed no relationship between implant survival rate and implant length. Nor was there any relationship with marginal bone loss.

Schincaglia et al. [32] compared short implants versus standard implants undergoing a sinus lift procedure. In this case, although the C/I ratio was found to be statistically significant between both groups, this had no effect on marginal bone loss. There was also no significant correlation between the survival rate of implants with respect to the length of both groups.

On the other hand, some authors found significant differences between the parameters studied, and the use of short implants which may have a greater impact.

Malchiodi et al. [33] in 2014 conducted a study in which they wanted to determine the influence of the $\mathrm{C} / \mathrm{I}$ ratio on bone loss and implant survival rate. To do this they used more than 150 short implants, comparing them with standard implants. In this case, they saw a significant relationship between marginal bone loss and implant loss when the $\mathrm{C} / \mathrm{I}$ ratio was increased. These results are contrary to those studied by the same authors in 2017 [29]. This could be mainly due to the difference in the number of implants in both studies, as in 2014 there were 259 short and standard implants, while in 2017 there were 113 implants. The follow-up time for both studies was three years.

In the study by Naenni et al. [34] they aimed to assess whether short implants had similar survival and bone loss rates as standard implants. In this case, significant differences were seen between implant length and survival rate, with short implants having a lower survival rate than standard implants. Significant differences were also seen in the C/I ratio between the two groups, although this had no influence on marginal bone loss. These differences in implant loss, according to the authors, can be attributed to the surfaces of the implants and the loading protocols used, which may vary from one study to another.

Rossi et al. [35] wanted to compare the clinical and radiographic findings obtained between short and standard implants over five years of follow-up. This study showed similar marginal bone loss in both groups, however, implant loss was seen to be greater in the short group. The authors attribute this event to the fact that three of the four short implants that failed were placed in the maxilla, and according to them, survival is slightly higher in the mandible compared to the maxilla.

Finally, we also found studies that show quite positive results regarding the use of short implants. In the case of Zadeh et al. [36] their main objective was to study whether bone loss occurred in a similar way in both groups of implants. They concluded that marginal bone loss was significantly lower in short implants than in standard implants. This, they said in the study, could have occurred as a consequence of overheating at the time of insertion of the long implants.

Blanes et al. [37] wanted to evaluate the influence of C/I ratio on marginal bone loss and the long-term survival rate of implants. In this case, they established an inverse relationship, it was seen 
that those restorations with an increased C/I ratio had less bone loss than those with a decreased C/I ratio. This could be attributed to the follow-up time, which in this study was 10 years.

As we can see, most of the studies analyzed conclude that there is no relationship between the use of short implants with an increased C/I ratio and marginal bone loss or implant survival. These results coincide with the quantitative analysis of our study.

However, when interpreting the results of the qualitative analysis, we must consider certain limitations. Among them is the time needed to follow up on the studies. Although most of them were between three and five years [25-27,29-31,33-36], there are several that also have a follow-up of only one year $[24,28,32]$. Given the absence of long-term longitudinal studies of more than 10 years on short implants it is difficult to define whether the passage of time affects the survival rate of short implants.

Finally, the splinting of the restorations should also be considered. It has been seen that when they are splinted there is a better distribution of the occlusal loads between the implants, thus reducing stress and increasing the stability of the restorations $[37,38]$. In some of the studies analyzed, the authors use both simple and splinted crowns $[25,29,30,33,37]$, but only one of them specifies the number of short and standard implants that use one or the other [25]. Therefore, it is not possible to analyze the influence of the $\mathrm{C} / \mathrm{I}$ ratio with this parameter.

\section{Conclusions}

After having systematically reviewed the scientific literature regarding the use of short implants for the prosthetic rehabilitation of partially or totally edentulous patients, we can conclude, taking into account the limitations of this study, the following:

- Short implants have a survival and bone loss rate similar to those of conventional length.

- As for the parameter implant length, no statistical significance has been established in terms of its influence on bone or implant loss, but in the latter case (implant loss) a value close to statistical significance is evident.

- The parameter implant diameter has not been established as statistically significant in terms of its influence on bone or implant loss.

- Finally, the parameter crown/implant ratio of the implants has also not been established as being statistically significant in terms of its influence on bone or implant loss.

Author Contributions: All of the authors contributed with the writing, review, and editing of the study. Main author and development of systematic review: A.T.-A., collaboration in systematic review and verification of results: J.F.M.-F., R.A.-P., and L.F.-E., development of the manuscript: A.T.-A., meta-analysis and statistical analysis: J.M.M.-C. and C.L.-R. All authors have read and agreed to the published version of the manuscript.

Funding: This research received no external funding.

Conflicts of Interest: This manuscript has not been published and is not under consideration for publication elsewhere. We have no conflicts of interest to disclose and all authors have approved the manuscript, agreeing with its submission.

\section{References}

1. Lemos, C.A.A.; Ferro-Alves, M.L.; Okamoto, R.; Mendonça, M.R.; Pellizzer, E.P. Short dental implants versus standard dental implants placed in the posterior jaws: A systematic review and meta-analysis. J. Dent. 2016, 47, 8-17. [CrossRef] [PubMed]

2. Okada, S.; Koretake, K.; Miyamoto, Y.; Oue, H.; Akagawa, Y. Increased Crown-To-Implant Ratio May Not Be a Risk Factor for Dental Implant Failure under Appropriate Plaque Control. PLoS ONE 2013, 8, 1-7. [CrossRef] [PubMed]

3. Misch, C.E. Implantología Contemporánea, 3rd ed.; Elsevier: Barcelona, España, 2009.

4. Atieh, M.A.; Zadeh, H.; Stanford, C.M.; Cooper, L.F. Survival of short dental implants for treatment of posterior partial edentulism: A systematic review. Int. J. Oral Maxillofac. Implant. 2012, 27, 1323-1331. 
5. Malchiodi, L.; Giacomazzi, E.; Cucchi, A.; Ricciotti, G.; Caricasulo, R.; Bertossi, D.; Gherlone, E. Relationship between crestal bone levels and crown-to-implant ratio of ultra-short implants with a microrough surface: A prospective study with 48 months of follow-up. J. Oral Implantol. 2019, 45, 18-28. [CrossRef] [PubMed]

6. Lombardo, G.; Pighi, J.; Marincola, M.; Corrocher, G.; Simancas-Pallares, M.; Nocini, P.F. Cumulative Success Rate of Short and Ultrashort Implants Supporting Single Crowns in the Posterior Maxilla: A 3-Year Retrospective Study. Int. J. Dent. 2017, 2017, 8434281. [CrossRef] [PubMed]

7. Ali, S.A.; Karthigeyan, S.; Deivanai, M.; Kumar, A. Implant rehabilitation for atrophic maxilla: A review. J. Indian Prosthodont. Soc. 2014, 14, 196-207. [CrossRef] [PubMed]

8. Misch, C.E.; Polido, W. A “Graft Less” Approach for Dental Implant Placement in Posterior Edentulous Sites. Int. J. Periodontics Restor. Dent. 2019, 39, 771-779. [CrossRef]

9. Schwartz, S.R. Short Implants: Are They a Viable Option in Implant Dentistry? Dent. Clin. N. Am. 2015, 59, 317-328. [CrossRef]

10. Nisand, D.; Renouard, F. Short implant in limited bone volume. Periodontology 2000 2014, 66, 72-96. [CrossRef]

11. Benlidayi, M.E.; Ucar, Y.; Tatli, U.; Ekren, O.; Evlice, B.; Kisa, H.I.; Baksi, U. Short implants versus standard implants: Midterm outcomes of a clinical study. Implant. Dent. 2018, 27, 95-100. [CrossRef]

12. Becerra-santos, G.; Becerra-moreno, N. Clinical considerations of the implants in posterior areas. CES Odontol. 2014, 27, 75-89.

13. Al-Hashedi, A.A.; Ali, T.B.T.; Yunus, N. Short dental implants: An emerging concept in implant treatment. Quintessence Int. 2014, 45, 499-514. [PubMed]

14. Neugebauer, J.; Nickenig, H.J.; Zöller, J.E. Guideline: Update on short, angulated and diameter-reduced implants. Eur. Assoc. Dent. Implantol. 2016, 1-9.

15. Thoma, D.S.; Zeltner, M.; Hüsler, J.; Hämmerle, C.H.F.; Jung, R.E. EAO Supplement Working Group 4-EAO CC 2015 Short implants versus sinus lifting with longer implants to restore the posterior maxilla: A systematic review. Clin. Oral Implant. Res. 2015, 26, 154-169. [CrossRef] [PubMed]

16. Fan, T.; Li, Y.; Deng, W.W.; Wu, T.; Zhang, W. Short Implants (5 to $8 \mathrm{~mm}$ ) Versus Longer Implants (>8 mm) with Sinus Lifting in Atrophic Posterior Maxilla: A Meta-Analysis of RCTs. Clin. Implant. Dent. Relat. Res. 2017, 19, 207-215. [CrossRef]

17. Hof, M.; Pommer, B.; Zukic, N.; Vasak, C.; Lorenzoni, M.; Zechner, W. Influence of prosthetic parameters on peri-implant bone resorption in the first year of loading: A multi-factorial analysis. Clin. Implant. Dent. Relat. Res. 2015, 17, 183-191. [CrossRef]

18. Quaranta, A.; Piemontese, M.; Rappelli, G.; Sammartino, G.; Procaccini, M. Technical and biological complications related to crown to implant ratio: A systematic review. Implant. Dent. 2014, 23, $180-187$. [CrossRef]

19. Rokni, S.; Todescan, R.; Watson, P.; Pharoah, M.; Adegbembo, A.O.; Deporter, D. An assessment of crown-to-root ratios with short sintered porous-surfaced implants supporting prostheses in partially edentulous patients. Int. J. Oral Maxillofac. Implant. 2005, 20, 69-76.

20. Urdaneta, R.; Rodriguez, S.; McNeil, D.C.; Weed, M.; Chuang, S.K. The effect of increased crown-to-implant ratio on single-tooth locking-taper implants. Int. J. Oral Maxillofac. Implant. 2010, 25, 729-743.

21. Anitua, E.; Piñas, L.; Orive, G. Retrospective study of short and extra-short implants placed in posterior regions: Influence of crown-to-implant ratio on marginal bone loss. Clin. Implant. Dent. Relat. Res. 2015, 17, 102-110. [CrossRef]

22. Wells, G.A.; Shea, B.; O'Connell, D.; Peterson, J.; Welch, V.; Losos, M.; Tugwell, P. The Newcastle-Ottawa Scale(NOS) for assessing the quality of nonrandomised studies in meta-analyses. Eur. J. Epidemiol. 2010, 25, 603-605.

23. Kim, Y.K.; Yun, P.Y.; Yi, Y.J.; Bae, J.H.; Kim, S.B.; Ahn, G.J. One-year prospective study of 7-mm-long implants in the mandible: Installation technique and crown/implant ratio of 1.5 or less. J. Oral Implantol. 2015, 41, 30-35. [CrossRef] [PubMed]

24. Adánez, M.H.; Brezavšček, M.; Vach, K.; Fonseca, M.; Att, W. Clinical and radiographic evaluation of short implants placed in the posterior mandible: A 1-year pilot split-mouth study. J. Oral Implantol. 2018, 44, 250-259. [CrossRef]

25. Guarnieri, R.; Di Nardo, D.; Gaimari, G.; Miccoli, G.; Testarelli, L. Short vs. Standard Laser-Microgrooved Implants Supporting Single and Splinted Crowns: A Prospective Study with 3 Years Follow-Up. J. Prosthodont. 2019, 28, 771-779. [CrossRef] [PubMed] 
26. Sahrmann, P.; Naenni, N.; Jung, R.E.; Held, U.; Truninger, T.; Hämmerle, C.H.F.; Attin, T.; Schmidlin, P.R. Success of 6-mm implants with single-tooth restorations: A 3-year randomized controlled clinical trial. J. Dent. Res. 2016, 95, 623-628. [CrossRef] [PubMed]

27. Hadzik, J.; Krawiec, M.; Sławecki, K.; Kunert-Keil, C.; Dominiak, M.; Gedrange, T. The Influence of the Crown-Implant Ratio on the Crestal Bone Level and Implant Secondary Stability: 36-Month Clinical Study. Biomed. Res. Int. 2018, 1-7. [CrossRef] [PubMed]

28. Ghariani, L.; Segaan, L.; Rayyan, M.M.; Galli, S.; Jimbo, R.; Ibrahim, A. Does crown/implant ratio influence the survival and marginal bone level of short single implants in the mandibular molar? A preliminary investigation consisting of 12 patients. J. Oral Rehabil. 2016, 43, 127-135. [CrossRef]

29. Malchiodi, L.; Caricasulo, R.; Cucchi, A.; Vinci, R.; Agliardi, E.; Gherlone, E. Evaluation of Ultrashort and Longer Implants with Microrough Surfaces: Results of a 24- to 36-Month Prospective Study. Int. J. Oral Maxillofac. Implant. 2017, 32, 171-179. [CrossRef]

30. Mangano, F.; Frezzato, I.; Frezzato, A.; Veronesi, G.; Mortellaro, C.; Mangano, C. The effect of crown-to-implant ratio on the clinical performance of extra-short locking-taper implants. J. Craniofac. Surg. 2016, 27, 675-681. [CrossRef]

31. Pohl, V.; Thoma, D.S. Sporniak-Tutak, K.; Garcia-Garcia, A.; Taylor, T.D.; Haas, R.; Hämmerle, C.H.F. Short dental implants $(6 \mathrm{~mm})$ versus long dental implants $(11-15 \mathrm{~mm})$ in combination with sinus floor elevation procedures: 3-year results from a multicentre, randomized, controlled clinical trial. J. Clin. Periodontol. 2017, 44, 438-445.

32. Schincaglia, G.P.; Thoma, D.S.; Haas, R.; Tutak, M.; Garcia, A.; Taylor, T.D.; Hämmerle, C.H.F. Randomized controlled multicenter study comparing short dental implants $(6 \mathrm{~mm})$ versus longer dental implants (11-15 mm) in combination with sinus floor elevation procedures. Part 2: Clinical and radiographic outcomes at 1 year of loading. J. Clin. Periodontol. 2015, 42, 1042-1051. [CrossRef] [PubMed]

33. Malchiodi, L.; Cucchi, A.; Ghensi, P.; Consonni, D.; Nocini, P.F. Influence of crown-implant ratio on implant success rates and crestal bone levels: A 36-month follow-up prospective study. Clin. Oral Implant. Res. 2014, 25, 240-251. [CrossRef] [PubMed]

34. Naenni, N.; Sahrmann, P.; Schmidlin, P.R.; Attin, T.; Wiedemeier, D.B.; Sapata, V.; Hämmerle, C.H.F.; Jung, R.E. Five-Year Survival of Short Single-Tooth Implants (6 mm): A Randomized Controlled Clinical Trial. J. Dent. Res. 2018, 97, 1-6. [CrossRef] [PubMed]

35. Rossi, F.; Botticelli, D.; Cesaretti, G.; De Santis, E.; Storelli, S.; Lang, N.P. Use of short implants (6 mm) in a single-tooth replacement: A 5-year follow-up prospective randomized controlled multicenter clinical study. Clin. Oral Implant. Res. 2016, 27, 458-464. [CrossRef]

36. Zadeh, H.H.; Guljé, F.; Palmer, P.J.; Abrahamsson, I.; Chen, S.; Mahallati, R.; Stanford, C.M. Marginal bone level and survival of short and standard-length implants after 3 years: An Open Multi-Center Randomized Controlled Clinical Trial. Clin. Oral Implant. Res. 2018, 29, 894-906. [CrossRef]

37. Blanes, R.J.; Bernard, J.P.; Blanes, Z.M.; Belser, U.C. A 10-year prospective study of ITI dental implants placed in the posterior region. II: Influence of the crown-to-implant ratio and different prosthetic treatment modalities on crestal bone loss. Clin. Oral Implant. Res. 2007, 18, 699-706. [CrossRef]

38. Nissan, J.; Gross, O.; Ghelfan, O.; Priel, I.; Gross, M.; Chaushu, G. The effect of splinting implant-supported restorations on stress distribution of different crown-implant ratios and crown height spaces. J. Oral Maxillofac. Surg. 2011, 69, 2990-2994. [CrossRef]

(C) 2020 by the authors. Licensee MDPI, Basel, Switzerland. This article is an open access article distributed under the terms and conditions of the Creative Commons Attribution (CC BY) license (http://creativecommons.org/licenses/by/4.0/). 